\title{
Application of Sediment Runoff Model to the Wlingi Reservoir Watershed, Indonesia
}

\author{
Kurdianto Idi Rahman ${ }^{1}$, Dian Sisinggih ${ }^{2}$, Runi Asmaranto ${ }^{2}$ \\ ${ }^{1}$ Jasa Tirta I Public Corporation, Malang, 65145, Indonesia \\ ${ }^{2}$ Water Resources Engineering Department, Universitas Brawijaya, Malang, 65145, \\ Indonesia \\ kurdi.rahman@gmail.com
}

Received 31-12-2019; accepted 19-02-2020

\begin{abstract}
Sedimentation is the main problem in Wlingi reservoirs. They are suffering from severe watershed erosion and a heavy load of volcanic ash ejected from the eruption of Mount Kelud. Wlingi reservoir is significantly affected by recurrent volcanic activities of Mount Kelud. After the 2014 eruption, the capacity of Wlingi reservoirs decreased by $82.5 \%$ or only 3.70 million $\mathrm{m}^{3}$ from the initial capacity of 24 million $\mathrm{m}^{3}$. To analyze the impact of volcanic eruption disaster on reservoir sedimentation an integrated numerical model of sediment is required. The Fujiyama model is an integrated sediment runoff model using a basin model composed of unit channels and unit slopes. The model seems suitable for a mountainous basin. The simulation results from the model explain that the mechanism of transporting sediment into the Wlingi Reservoir can be explained based on the type of sediment transport. The movement of sediment originating from Kelud Mountain in Kali Lekso is strongly influenced by rainfall duration compared to the intensity of the rainfall. Also, the simulation model results explained that the mechanism of sediment transportation is dominated by suspended load or bed load which when large discharges will move with the mechanism of suspended load sediment transport.
\end{abstract}

Keywords: Fujiyama Model, Sedimentation, Wlingi Watershed.

\section{Introduction}

Reservoir Sustainability at this time are increasingly threatened because of the high rate of sedimentation occurs. Sedimentation is one of the main problems in the reservoir in the Brantas River Basin. The Wlingi reservoir, which is part of a reservoir system in the Brantas Basin, has rapidly lost its storage capacity. The decrease in reservoir storage affects water allocation for energy generation, irrigation and raw water fulfillment during the dry season and flood control capability in the rainy season [1]. In addition, the Wlingi Reservoir is greatly affected by the eruption activity of Mount Kelud, which is one of the most active volcanoes on the island of Java, Indonesia [2]. The eruption of Mount Kelud in 1990 produced sediment volumes which greatly influenced sedimentation in the Wlingi and Lodoyo Reservoirs [3]. The latest data for 2016 shows that the total reservoir capacity of the Wlingi Reservoir has decreased by $82.5 \%$ or only 4.45 million $\mathrm{m}^{3}$ from the initial capacity 24 million $\mathrm{m}^{3}$ [1]. At now, not

Cite this as: Rahman, K., Sisinggih, D., \& Asmaranto, R. (2020). Application of Sediment Runoff Model to the Wlingi Reservoir Watershed, Indonesia. Civil and Environmental Science Journal, 3(1), pp.10-17. doi: https://doi.org/10.21776/ub.civense.2020.00301.2 
many numerical models are used to estimating erosion and sedimentation of reservoirs due to volcanic eruptions were applied in Indonesia. This paper will discuss the sedimentation analysis of the Wlingi Reservoir using the sediment runoff model to predict erosion and sedimentation due to volcanic material. It can be used as a reference in planning and management decision on related sedimentation action activities in the Wlingi Reservoir.

\section{Calculations Method and Conditions}

\subsection{Target Area}

The target area is Wlingi reservoir watershed (Fig 1). The area of watershed is around $697 \mathrm{~km}^{2}$ and elevation of this watershed is distributed from $145 \mathrm{~m}$ to $2850 \mathrm{~m}$. The mean annual precipitation was $2.227 \mathrm{~mm}$. In this area there are 4 rain gauge stations which are operated by Jasa Tirta I Public Corporation (PJT I), the location of those station are shown in Fig 1.

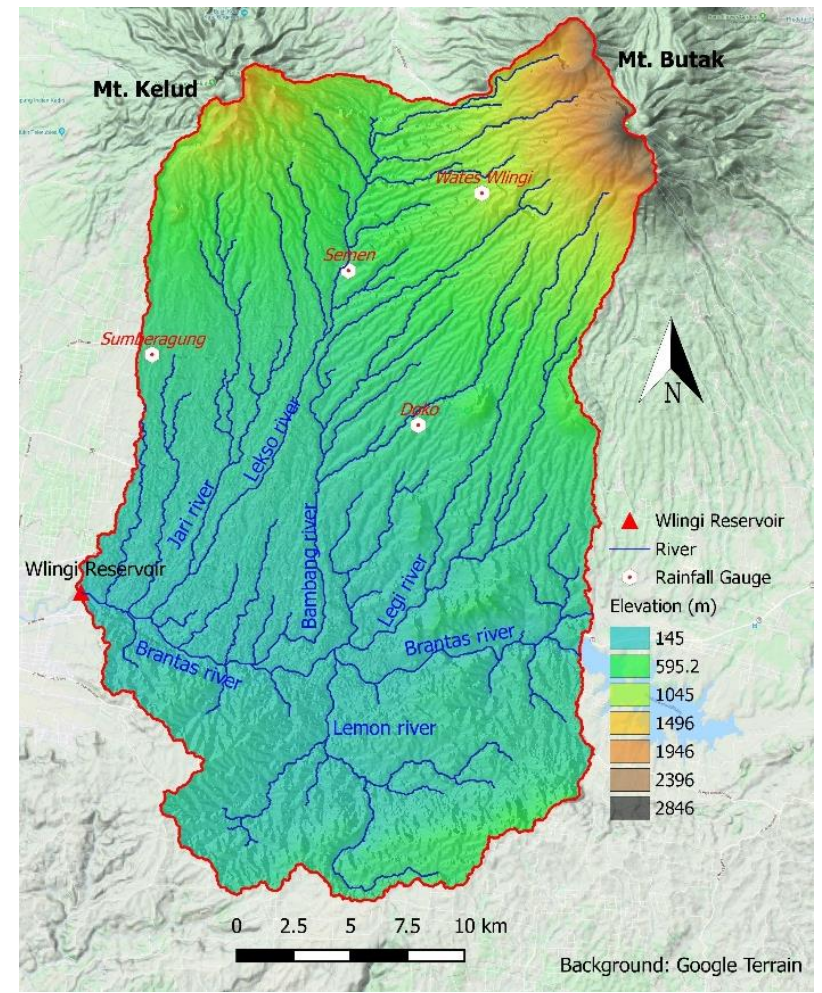

Figure 1. Research area in the wlingi reservoir watershed

\subsection{Method}

In this simulation, we applied Yamanoi and Fujita's model [4], the sediment runoff model as known as Fujiyama Model. The model can calculate the water and sediment discharge and sediment deposition in the unit channel network. It mainly requires the rainfall conditions, topographical conditions, and grain size distribution of the river bed and produced sediment material.

The model was developed by integrating sub-process models of sediment production, sediment supply, and sediment transport using basin model composed of unit channels and unit slopes (Fig. 2). The model was constructed based on unit channel and unit slope basin model by Egashira \& Matsuki model [5] as shown in Fig. 3 [6]. A unit channel is defined as a section in the river between two adjacent confluence points. The two slopes that connect with both sides of a unit channel were defined as unit slopes. A unit channel was assumed to be straight and uniform. 


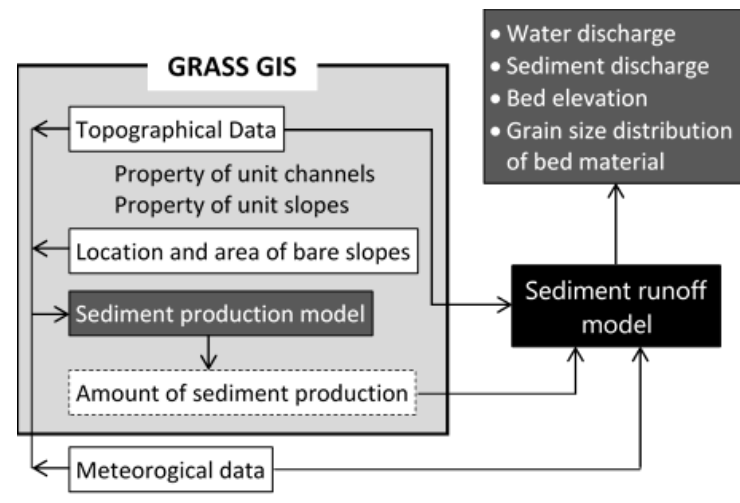

Figure 2. Conceptual of Fujiyama Model.

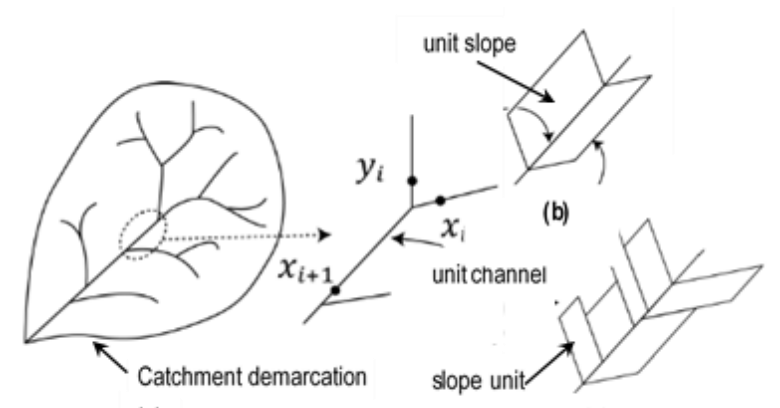

(a)

(c)

Figure 3. Unit channel and unit slopes, (a) channel units with two inflow points and one outflow (b) each channel unit has two slope units and (c) each slope unit can be divided into several slope sub-units based on the value of the slope aspect and other parameters.

The unit channels and unit slopes data were extracted from DEM employing GRASS-GIS. The length of each unit channel was extracted automatically using GIS, and the inclination of the unit channel was calculated by dividing the difference in the elevation between the upstream end and the downstream end by the length of the channel. The area of each unit slope was then calculated using GIS by measuring the projected area of each slope, and the angle was calculated as the average angle on the actual slope [6]. The sediment transport model of Egashira \& Matsuki was employed and linked to the sediment supply model. This model simulates the change in bed elevation in the unit channel and in the grainsize distribution of bed material. Rainfall runoff also was simultaneously simulated using the kinematic wave method and Darcy's law. The supplied sediment was expressed as riverbed evolution at the nearest unit channel. Each model is connected and integrated using GRASS-GIS. The timing and volume of sediment production are computed by the sediment production model from the topographical data and meteorogical data. Using data on sediment production, the sediment supply model and transport model are employed simultaneously. As a result of this application, the water discharge, sediment discharge, and riverbed elevation can be obtained [4].

\subsection{Conditions}

The unit slopes and unit channels were extracted using the 30m mesh DEM data from SRTM and refined to $10 \mathrm{~m}$ mesh. The grain size distribution data was obtained by laboratory analisis from lekso, jari and semut river bed material (Fig. 4). Rainfall data using the average daily rainfall data from 4 stations in the target area in 2016 (Fig. 5).

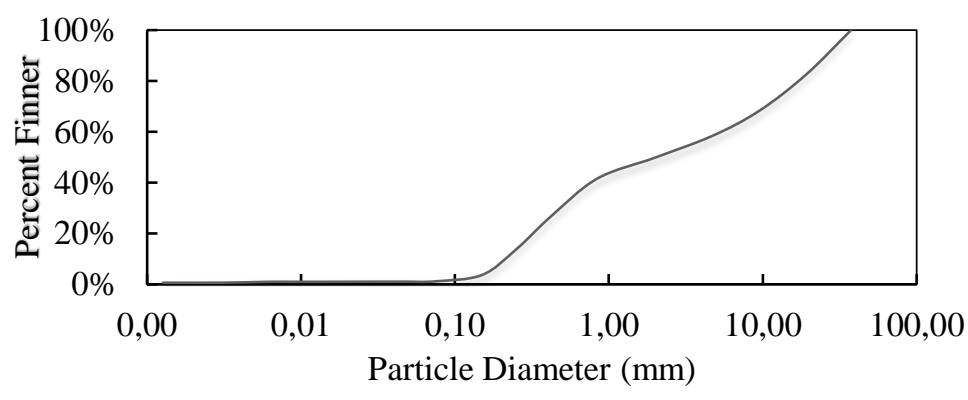

Figure 4. Grain size distribution data. 


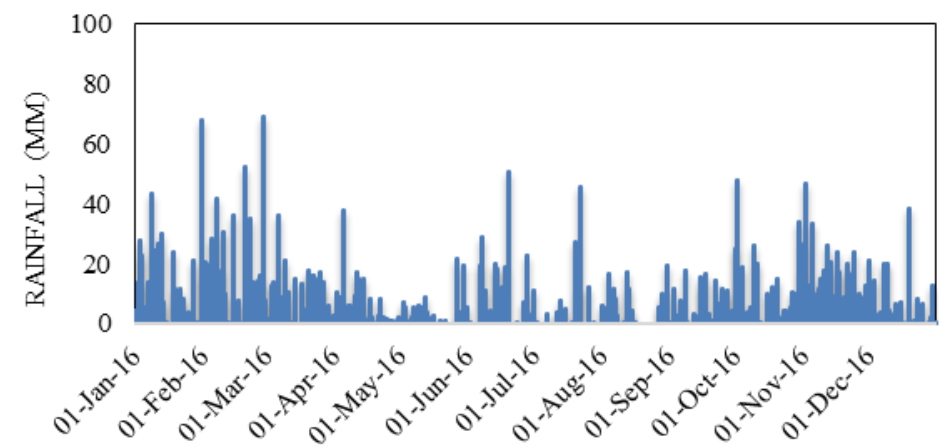

Figure 5. Rainfall data in 2016.

\section{Result and Discussion}

\subsection{Water and Sediment Discharge}

The calculated results for water discharge were higher than the observed results as shown in Fig. 6. This possibility is because the rainfall simulation process which in the model uses uniform rainfall. So by using the uniform rainfall, the calculation assumption will get a higher value than the observation data. The consequence is the cumulative value of sediments deposited in the Wlingi reservoir in 2016 reached a value of $598,824 \mathrm{~m}^{3}$ (shown in Fig. 7), higher than the sediment value from the analysis of historical reservoir data of $500,000 \mathrm{~m}^{3} /$ year.

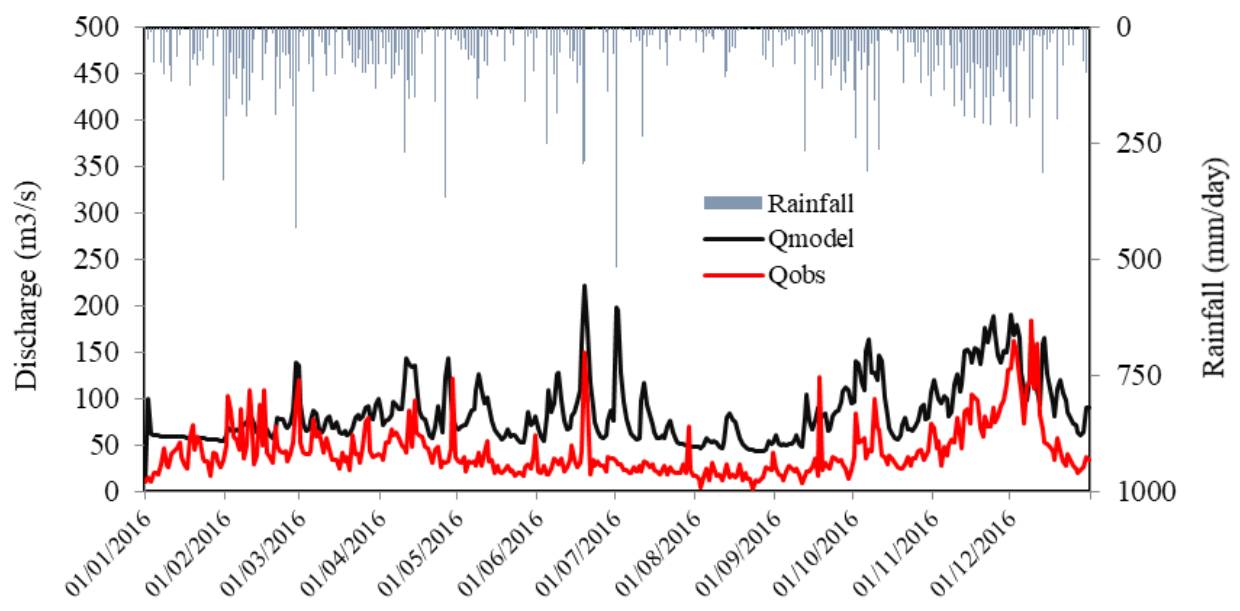

Figure 6. Rainfall-runoff discharge in Wlingi Reservoir Watershed calculation by the model

\subsection{Sediment Transport}

The mechanism of sediment transportation is dominated by suspended load sediments, or sediment bed loads that when large discharges will move with the suspended load sediment transport mechanism. For bed load movements with a basic flow mechanism, it cannot be described in the model. However, agradation and degradation in the process of riverbed change occurred during 2016.

From the results of the running model to simulate sediment flow in the Wlingi watershed, shows that the movement of sediments occurs in moderate and high intensity rain conditions. From the results of the running model for 1 year, it is known that the movement of each type of sediment transport modes both originating sediment from the slopes of Mount Kelud and those from the southern region of the Wlingi Reservoir. Sediment transport in the rainy season occurs in all major tributaries that enter through the Wlingi Reservoir. 


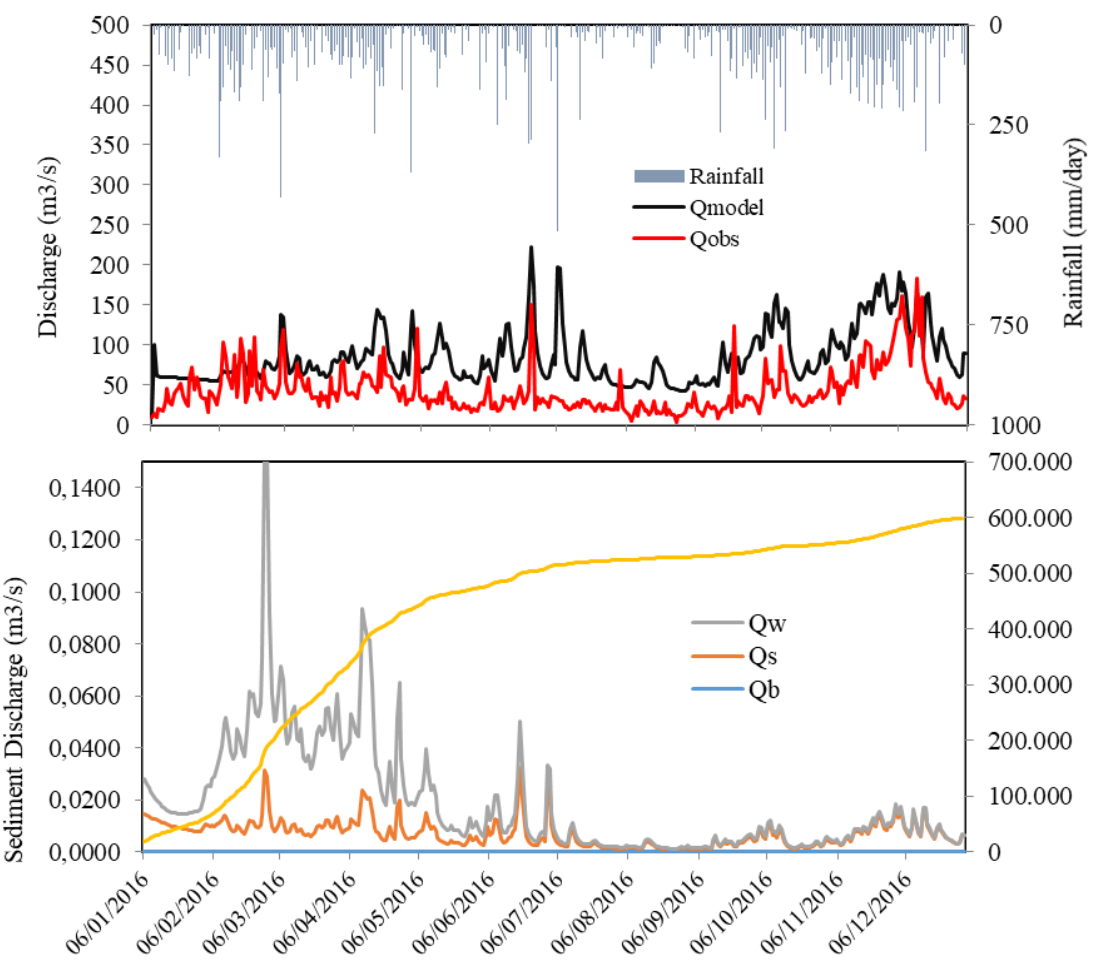

Figure 7. Water and sediment discharge calculation by the model

The movement of the bed load material is strongly influenced by the duration of the existing rainfall compared to the intensity of the rainfall that occurred. Short duration rainfall ( $<6$ hours) occurred at the upstream of Kali Lekso was unable to generate enough runoff to move river material to downstream area. Its usually occurs in April-May when will enter the dry season. As a consequence of sediment flow, river bed changes only occur at the bottom of the upper Lekso River, where although the runoff discharge is low, the relatively steep river slope will be able to erode the river bed. When the slope of the river is not steep enough, the degradation process does not occur and the material will pile up, causing channel agradation. Conversely, when fairly long duration rainfall ( $>6$ hours) occurs, usually in November-December, runoff discharges that occur on the land will be quite significant when it becomes a flood discharge in Kali Lekso and Kali Bambang can cause significant downward movement of bed material. The process of changing the river bed occurs when a long enough duration rainfall able to bring bed material moving at a longer range and enter the reservoir. The agradation and degradation process shown in Fig. 7.

Unlike the movement of bed load material, for suspended load material, the sediment discharge increasing will be greatly influenced by the amount of runoff or flood discharge that occurs compared to rainfall duration. From the rainfall-runoff and sediment transport process in the model, obtained that the amount of suspended load sediment entering the Wlingi Reservoir has a linear relationship with the upstream rainfall events both in intensity and amount of rainfall. Sediment transport for suspended load occurs for short duration rainfall both upstream of Lekso river and Lemon river. Its will bring suspended sediment material that originates from the upstream trough the reservoirs. Likewise, when it long duration rainfall, the resulting runoff discharge becomes higher so that the dominance of sediment transport is no longer by suspended load sediment but by bed load material transport. Increased water discharge in the channel makes the flow velocity increase far beyond the initial threshold of the suspended moving grain level, so that the movement of the suspended load transport material granules becomes the wash load along the channel. Fig. 8 illustrates the process of transporting sediment for suspended load material that occurs in the Wlingi watershed. 

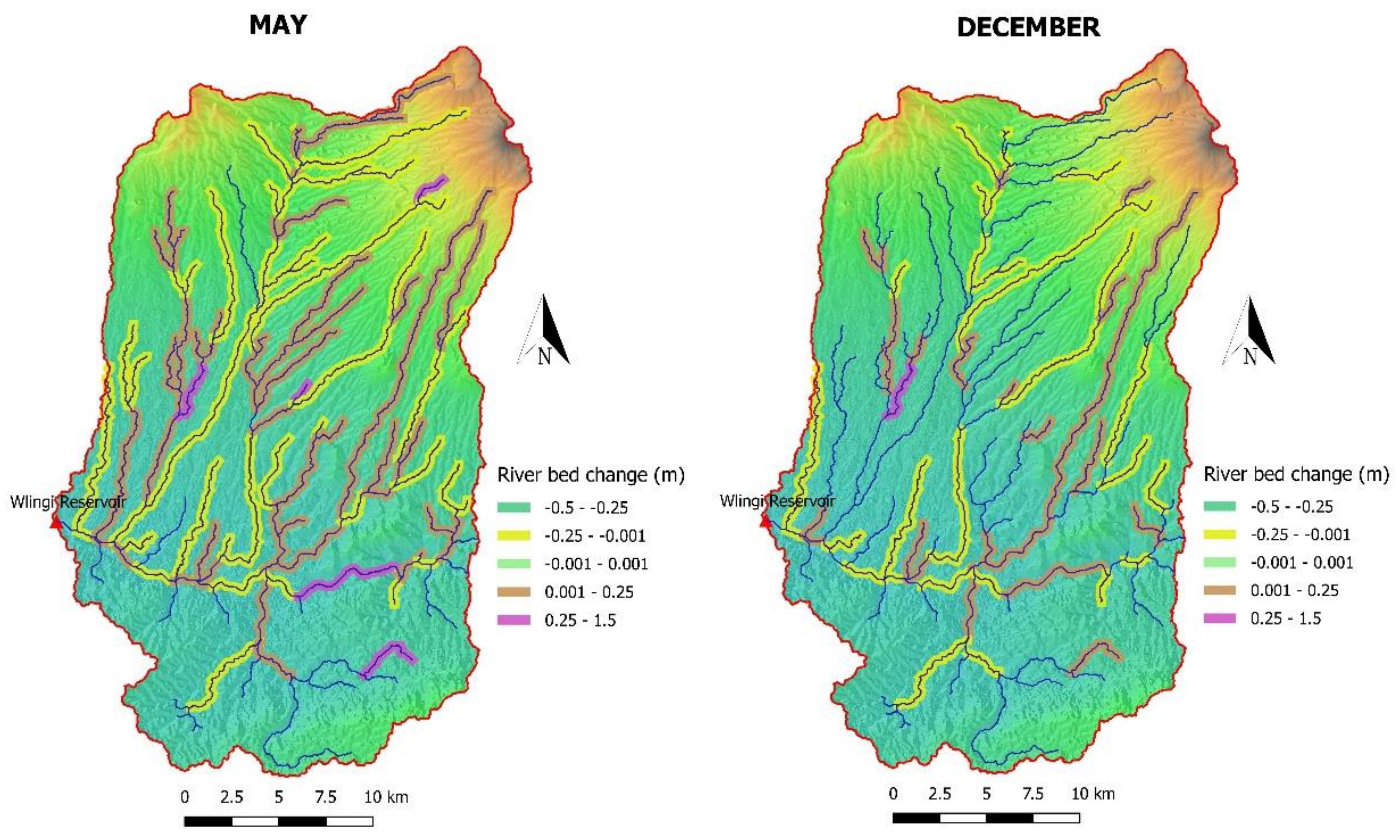

Figure 7. River bed change (agradation and degradation)
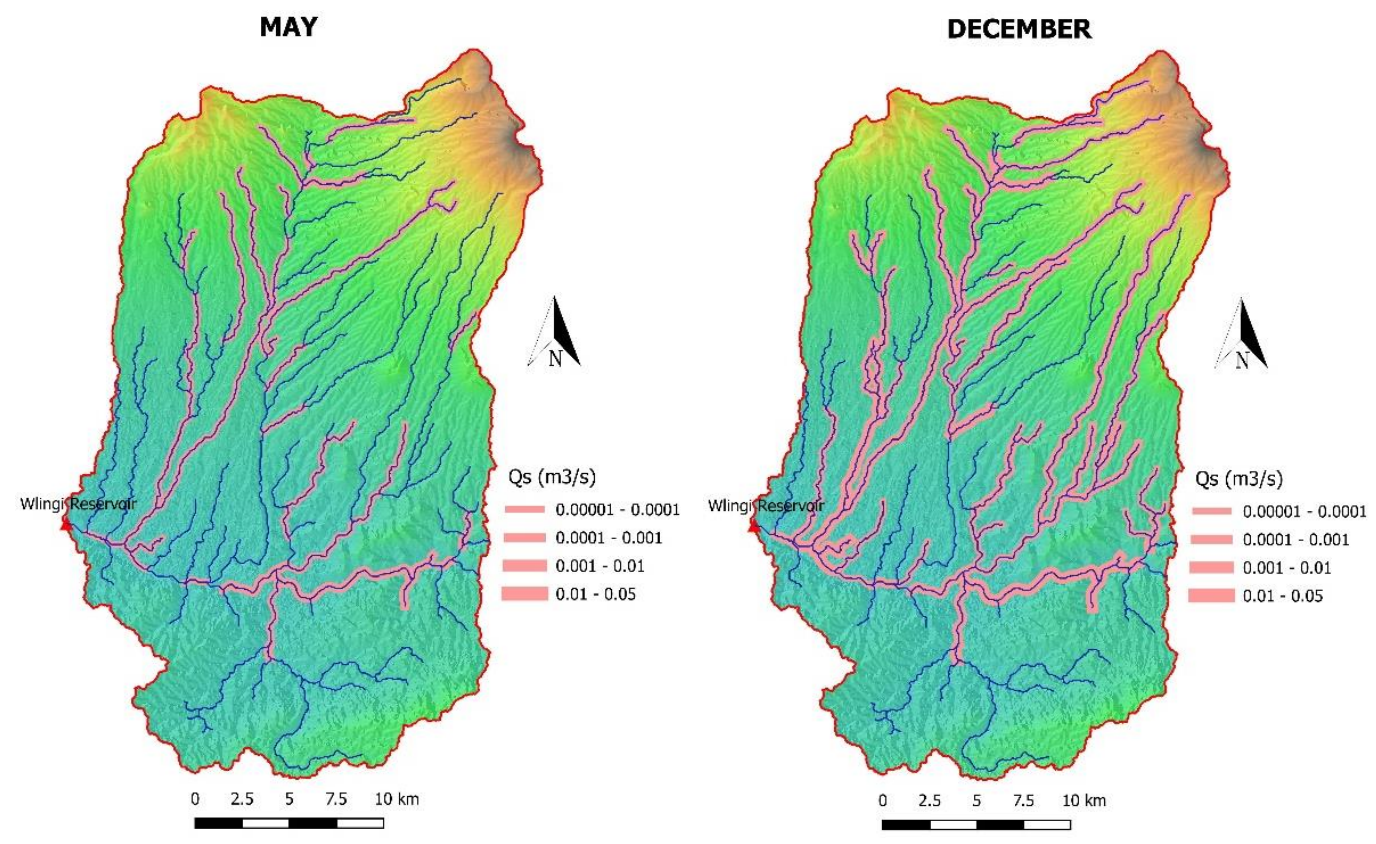

Figure 8. Suspended load sediment transport

Comparable to the movement of bed load and suspended load material transport, for wash load almost does not occur when a small runoff discharges due to short duration rainfall. As explained in the previous discussion when the discharge increases due to a long duration rainfall, an increase in wash load transport occurs in all tributaries in the Wlingi reservoir. Fig. 9 illustrates the process of transporting sediment for wash load material that occurs in the Wlingi watershed. 

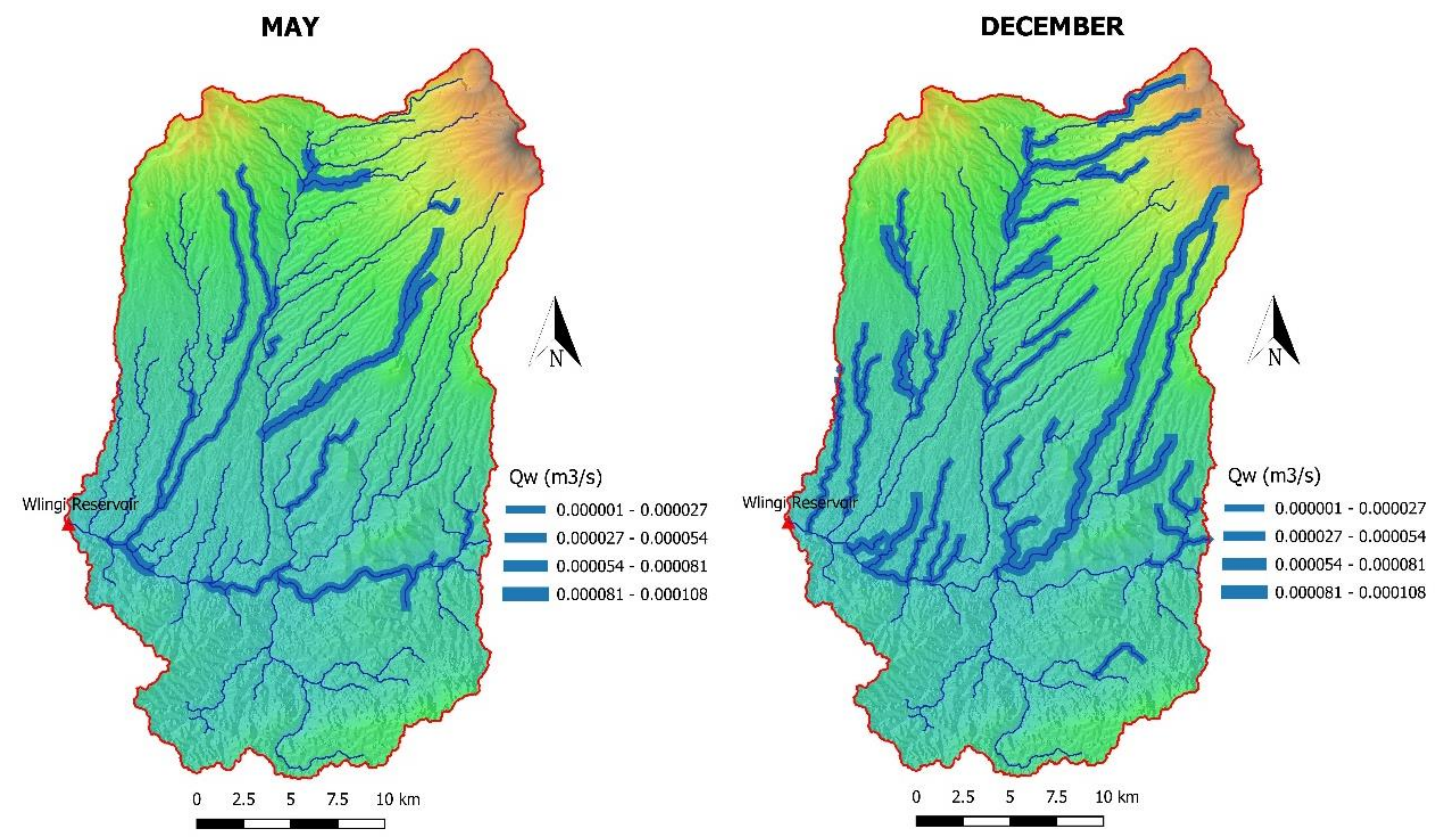

Figure 9. Wash load sediment transport

Based on the results of the movement of sediment material from the model, it can be described that the material entering the Wlingi Reservoir is as follows. Volcanic eruption material is dominated by the northern region which flows through the Lekso river. Whereas material from land erosion originates from the slopes of Mount Butak through the Bambang river and Legi river. From the southern area the catchment area of material erosion resulting from land flows through Lemon river.

\section{Conclusions}

A result of the calculation of this model, sediment runoff model can be used to simulate annual sediment discharge. The result of runoff discharge from the model was slightly greater than the observation discharge. So, the total cumulative sediment calcuated by model is greater than the historical reservoir sediment data. The mechanism of sediment transportation is dominated by suspended load sediments, or sediment bed loads that when large discharges will move with the suspended load sediment transport mechanism. For bed load movements with a basic flow mechanism, it cannot be described in the model. However, agradation and degradation in the process of riverbed change occurred during 2016. In general, it can be stated that the results of applying the model are quite good. Of course, there are still shortcomings that become a gap to be improved in future research.

\section{Acknowledgments}

The authors thank to Disaster Prevention Research Institute Kyoto University (DPRI-KU) Japan, Departement of Water Resource Brawijaya University (WRE-UB) and Jasa Tirta I Public Corporation (PJT-I) for research support and mutual collaboration work for this study.

\section{References}

[1] PJT I. 2016. Kajian Kapasitas Tampungan Waduk Sengguruh-Sutami-Lahor dan Wlingi-Lodoyo. Malang : Penelitian oleh Biro Penelitian dan Pengembangan.

[2] Hidayat, F., Juwono, P. T., Suharyanto, A., Pujiraharjo, A., Legono, D., Sisinggih, D., Neill, D., Fujita, M. \& Sumi, T. 2017. Assesment of Sedimentation in Wlingi and Lodoyo Reservoirs: A Secondary Disaster Following the 2014 Eruption of Mt. Kelud, Indonesia. Journal of Disaster Research, Vol. 12 No. 3.

[3] Soekistijono, Hidayat, F. \& Harnanto, A. 2005. Coordinated Sediment Flushing in Wlingi- 
Lodoyo Reservoirs and the Study of Its Benefits and Effect to Water Quality and Ecosystem in Downstream Reaches. International Seminar on Echohydrology. Denpasar.

[4] Kazuki Yamanoi and Masaharu Fujita, Development of a Combined Model of Sediment Production, Supply and Transport, and Its Application to a Mountainous Basin, Journal of JSCE, Vol. 3, 224-229, 2015.

https://doi.org/10.2208/journalofjsce.3.1_224

[5] Egashira, S. \& Matsuki, T. 2000. A Method of Predicting Sediment Runoff Caused by Erosion of Stream Channel Bed. Annual Journal of Hydraulics Engineering. Japan Society of Civil Engineers 44.

[6] Masaharu Fujita, Kazuki Yamanoi and Hiroaki Izumiyama, A Combined Model of Sediment Production, Supply and Transport, Sediment Dinamycs: from the Summit to the Sea, Procedings of symposium, New Orleans, Lousiana, USA, 11-14 December 2014) (IAHS Publ. $367,2014)$.

doi:10.5194/piahs-367-357-2015 